\title{
ANALISIS KATA MAKIAN DALAM DRAMA KOMEDI SASAK OMJ (OOO MENU JARIN) SUATU KAJIAN SOSIOLINGUISTIK
}

\author{
${ }^{1}$ Hilpiatun, ${ }^{2} \mathrm{Akhmad}$ H. Mus, ${ }^{3} \mathrm{Habiburrahman}$ \\ 1,2,3 Pendidikan Bahasa Indonesia, Universitas Muhammadiyah Mataram, Indonesia \\ ${ }^{1}$ hilpiatun@gmail.com, ${ }^{2}$ akhmad@ummat.ac.id, ${ }^{3}$ habibpemuda@gmail.com
}

\section{INFO ARTIKEL}

\section{Riwayat Artikel:}

Diterima: $12-11-2018$

Disetujui: 20-01-2019

\section{Kata Kunci:}

Sosiolinguistik, Bahasa

Sasak, Kata makian

\section{Keywords: \\ Sociolinguistic, Sasak \\ language, word of food}

\begin{abstract}
Abstrak: Tujuan dari penelitian ini, yaitu 1) untuk mengetahui bentuk kata makian 2) untuk mengetahui fungsi kata makian 3) untuk mengetahui makna referensi kata makian. Metode penelitian ini, dengan teknik pengumpulan data menggunakan metode deskriptif kualitatif diantaranya teknik simak dan catat, yaitu penelitian menonton film komedi Sasak OMJ ( Ooo Menu Jarin). Hasil dari penelitian menunjukkan 1) bentuk kata makian yang terdapat pada film drama komedi Sasak OMJ (Ooo Menu Jarin) sebanyak 12 kata makian dan terdiri atas dua bentuk bahasa yaitu bentuk kata dasar dan bentuk frase. 2) fungsi kata makian yang terdapat pada film tersebut menurut pandangan Andersson dan Trudgiil ada empat fungsi yaitu a) fungsi "explerive" yang berarti penggunaan makian untuk menyatakan emosi dan tidak ditunjukkan langsung pada orang lain b) fungsi"abusive" yang berarti penggunaan makian yang langsung ditunjukkan pada orang lain c) fungsi "humorous" yang berarti penggunaan makian yang merujuk langsung pada orang lain, tetapi bukan dalam maksud menghina dan yang d) fungsi"auxiliary" yangberarti menggunakan makian yang tidak langsung merujuk pada orang lain, melainkan sekedar cara bicara (lezy speaking), yang sering kali tidak sungguh-sungguh. 3) Makna referensial kata makian yaitu, keadaan, binatang, benda-benda, bagian tubuh dan profesi.
\end{abstract}

ABSTRAK

\begin{abstract}
The purpose of this study, namely 1) to know the form of the word 2) to know the function of the word cuss 3) to know the meaning of the word reference. This method of research, with the technique of data collection using qualitative descriptive method including the reading and note-taking technique, which is the research to watch the comedy movies Sasak OMJ (Ooo Menu Jarin). The results of the study showed 1) the word form found in the comedy-drama Sasak OMJ (Ooo Menu Jarin) as many as 12 words and consists of two forms of basic word and phrase form. 2) The word function that exists in the film according to the views of Andersson and Trudgiil there are four functions of a) function "explerive" which means the use of cuss to declare emotions and not shown directly in others b) function "abusive" Which means the use of the stock is directly shown in others c) function "humorous" which means the use of the laboratory referring directly to others, but not in the intent of insults and the D) function "auxiliary" means using the Cuss That does not directly refer to other people, but rather just a lezy speaking, which is often not earnest. 3) referential meaning of the word cuss i.e., circumstances, animals, objects, body parts and professions.
\end{abstract}

\section{A. LATAR BELAKANG}

Berbicara tentang bahasa tentu bukan merupakan hal yang baru bagi Skehidupan manusia. Setiap manusia beraktifitas, pasti memahami dan menggunakan bahasa tertentu. Jadi, dapat dipertegas bahwa bahasa merupakan satu kebutuhan pokok dalam kehidupan manusia. tanpa bahasa manusia tidak berarti apa-apa dihadapan orang lain. Orang lain tidak memahami siapa dan bagaimana kita. Namun, ketika kita diajak untuk mendefinisikan apa 
itu bahasa, ternyata tidak semua penutur bahasa dapat menjelaskan dengan baik. Oleh karena itu perlu dipaparkan pengertian bahasa secara lengkap.

Ditinjau secara umum, bahasa dapat diartikan sebagai ucapan, pikiran dan perasaan seseorang yang disampaikan secara teratur dan digunakan sebagai alat komunikasi antara anggota masyarakat. Menurut Harimurti Kridaklaksa (1997) bahwa bahasa merupakan sistem lambang bunyi yang arbitrer, digunakan para anggota kelompok sosial untuk mengidentifikasi diri terhadap orang lain.

Bahasa dapat pula dilihat secara praktis dan teknis. Secara praktis, bahasa merupakan salah satu alat komunikasi berwujud sistem bunyi atau tulisan yang mempunyai makna tertentu, dipahami dan dihasilkan oleh alat ucapan manusia. secara teknis, bahasa merupakan seperangkat ujaran yang bermakna lengkap yang dihasilkan olah alat ucap manusia.

Mengungkapkan perasaannya dalam berkomunikasih yang mengandung fungsi dan makna yang lazim dalam arti yang sebenarnya. Oleh karena itu, peneliti sangat tertarik dan termotivasi untuk mengkaji “ Analisis Kata Makian Dalam Drama Komedi Sasak OMJ (Ooo Menu Jarin) Suatu Kajian Sosiol inguistik".

Penelitian mengangkat permasalahan tersebut karena, peneliti merasa makian yang terdapat dalam drama tersebut tidak lazimnya makian yang didengar, karena makian yang digunakan dalam film OMJ mengalami perubahan fungsi dan makna dari yang sebenarnya untuk memperlihatkan keakraban antar pemain di dalam drama tersebut selain itu penelitian juga merasa penelitian ini belum pernah dilakukan, khususnya tentang bentuk, fungsi, dan makna penggunaan kata makian pada drama komedi sasak OMJ (Ooo Menu Jurin).

\section{B. METODE PENELITIAN}

\section{Rancangan Penelitian}

Metode yang digunakan dalam penelitian ini adalah metode penelitian deskriptif kualintatif. Penelitian deskriptif kualintatif adalah penelitian yang berusaha memberikan gambaran secara sistematis, faktual, akurat, mengenai sifat-sifat populasi atas daerah tertentu (Arikunto, 2006: 145). Penelitian ini mendeskripsikan tentang menganalisis bentuk, fungsi dan makna referensial kata makian yang terdapat dalam film komedi Sasak OMJ (Ooo Menu Jarin).

\section{Data dan Sumber Data}

Data dalam penelitian ini yaitu bentuk, fungsi dan makna referensial kata makian yang terdapat dalam film komedi Sasak (OMJ). Sedangkan Sumber Data dari penelitian yaitu bersumber dari vidio film komedi Sasak OMJ (Ooo Menu Jarin) di Lombok Post TV.

\section{Metode Pengumpulan Data}

Mengingat jenis penelitian merupakan jenis penelitian pustaka maka penelitian ini dikumpulkan dengan menggunakan metode pengumpulan data sebagai berikut.

a. Metode simak

Di dalam metode ini, peneliti memperoleh data dengan menyimak penggunaan bahasa pada intaksi film komedi Sasak OMJ (Ooo Menu Jarin) yang diteliti.

b. Teknik catat

Teknik catat merupakan teknik yang dilakukan dengan cara mencatat data-data yang terdapat dalam film komedi Sasak OMJ (Ooo Menu Jarin) sebelum pencetakan, penulis terlebih dahulu mencari data dengan menonton. Menonton dilakukan dengan teliti untuk memperoleh data yang tepat. Prosedur dilakukan secara lebih singkat dapat dirincikan sebagai berikut : Menonton film komedi Sasak OMJ (Ooo Menu Jarin). Mencatat kata, frase, dan klausa yang dianggap sebagai bentuk-bentuk makian.

c. Metode Transkripsi Data

Metode transkrip data merupakan pengalihan tuturan yang berbentuk bunyi kedalam tulisan, senada dengan itu kata transkrip menurut Braraarmaja (1994: 301) yang berarti alih tulis. Jadi metode transkip merupakan cara pengumpulan data dengan jalan penyalinan (alih tulis), dalam hal ini penulis menyalin atau alih tulis tuturan yang dilakukan oleh para pemain film OMJ. Metode ini digunakan untuk menguraikan dan menganalisis dari data yang sudah ada agar dapat dipahami oleh pembaca dari hasil penelitian ini.

d. Metode Terjemahan 
Metode ini digunakan untuk mengubah bahasa asli (bahasa sasak) ke dalam bahasa indonesia dalam berinteraksi. Hasil terjemahan ini dimaksud untuk memudahkan pemahaman.

\section{Instrumen Penelitian}

Instrument pengumpulan data adalah alat atau fasilitas yang digunakan oleh peneliti dalam mengumpulkan data agar pekerjaannya lebih muudah dan hasilnya lebih baik, dalam arti lebih cermat, lengkap dan sistematis sehingga lebih mudah diolah (Arikunto, 2006: 160). Dalam penelitian ini instrument yang digunakan adalah alat tulis dan video.

\section{Metode Analisis Data}

Di dalam penelitian ini, peneliti menganalisis data dengan menggunakan metode "deskriptif kualitatif". Metode deskriptif kualitatif ialah suatu caara pengolahan data yang dilakukan dengan jaalan secara sistematis sehingga akan memperoleh kesimpulan umum (menyeluruh) mengenai permasalahan.

Adapun langkah-langkah dalam menganalisis data menggunakan metode deskriptif kuantitatif yaitu sebagaai berikut.

a. Identifikasi

Identifikasi merupakan penentuan atau penetapan identitas. Pada langkah ini, peneliti melakukan pengamatan dengan cara menonton dan menyimak secara berulangulang untuk mengumpulkan data sehingga dapat menemukan bentuk, fungsi dan makna referensial kata makian yang terdapat dalam film komedi Sasak OMJ (Ooo Menu Jarin).

b. Klarifikasi

Kegiatan klarifikasi dilakukaan dengan mengkelompokkan hasil simaan dari menonton film dengan cara memberikan pengkodean atau tanda terhadap kalimaat atau kata-kata yang berkaitan dengan masalah yang diteliti. Kegiatan ini dilakukan untuk mempermudah kegiatan analisis terhadap bentuk, fungsi dan makna referensial kata makian dalam drama komedi Sasak OMJ (Ooo Menu Jarin). Setelah penyajian data dilakukan kemudian dilanjutkan dengan analisis sehingga data tersebut bermakna dan dapat ditarik kesimpulannya.

\section{HASIL DAN PEMBAHASAN}

\section{Hasil penelitian}

Gambaran tentang film OMJ (Ooo Menu Jarin) Penelitian ini, tentang drama komedi Sasak OMJ (Ooo Menu Jarin) yang diperankan oleh beberapa artis dan aktor sebagai berikut :

a. Pemain utama
1) Ahyar Rosidi sebagai Miun
2) Dwi Winarti sebagai Odah
3) Beny Pratama sebagai Jenal

b. Pemain pembantu
1) Nurul hikmah
2) Zahrul fahmi

c. Abdan Syakur sebagai pemberi arahan

d. Azhar Zaini sebagai pengarahan cerita

e. Imam Sadikin sebagai arahan kamera

f. Risky Pratama sebagai pengoprasian kamera

g. Susy Sumadi sebagai bagian kostum

h. Zahrul Fahmi sebagai bagian properti

i. Rizky Pratama sebagai pengedit

j. Nasib Ikroman sebagai tanggung jawab produksi

k. Pratma Pictures $=$ Lombok Post TV

Kata-kata makian yang terdapat pada film drama komedi Sasak OMJ (Ooo Menu Jarin). Seperti dibawah ini.

Table 1. Film drama komedi Sasak OMJ (Ooo Menu Jarin).

\begin{tabular}{|l|l|l|l|}
\hline No & \multicolumn{1}{|c|}{ Glos } & \multicolumn{1}{|c|}{ Arti } & \multicolumn{1}{|c|}{ Episode } \\
\hline 1 & Jadiq & Haram & Episode 1 \\
\hline 2 & Sendes & Pezina & Episode 1 \\
\hline 3 & Berong & $\begin{array}{l}\text { Sejenis penyakit } \\
\text { menular (kusta) }\end{array}$ & Episode 2 \\
\hline 4 & Sampi & Sapi & Episode 3 \\
\hline 5 & Bangke & Bangkai & Episode 6 \\
\hline 6 & Train jaran & Kotoran kuda & Episode 3 \\
\hline 7 & Tain minyak & $\begin{array}{l}\text { Kotoran } \\
\text { minyaak }\end{array}$ & Episode 11 \\
\hline 8 & Tain mako & $\begin{array}{l}\text { Kotoran } \\
\text { tembakau }\end{array}$ & Episode 11 \\
\hline 9 & Tain petuq & $\begin{array}{l}\text { Kotoran burung } \\
\text { perkutuk }\end{array}$ & Episode 11 \\
\hline 10 & $\begin{array}{l}\text { Tolang } \\
\text { baloq papuk }\end{array}$ & $\begin{array}{l}\text { Tulang nenek } \\
\text { cicit }\end{array}$ & Episode 2 \\
\hline 11 & Tunggak elaq & Pangkal lidah & Episode 11 \\
\hline 12 & Batun mate & Bola mata & Episode 4 \\
\hline
\end{tabular}

\section{Kata Makian Dalan Drama Komedi Sasak OMJ (Ooo Menu Jarin)}

Makian merupakan ungkapan perasaan tertentu yang timbulnya disebabkan oleh dorongan yang 
bersifat kebahasaan dan nonkebahasaan. Hal yang bersifat kebahasaan berupa kata-kata yang diucapkan oleh seseorang yang dirasa tidak berkenan pada diri pemakai. Sebaagaai taanggaapan atas tindakan itu, si pemakai melampiaskan perasaannya melalui berbagaai makian. Sementara itu, hal yang bersifat nonkebahasaan biasanya menyangkut perbuatan seseorang atau peristiwa tertentu.

Kata makian yang digunakan para pemain film drama komedi Sasak OMJ (Ooo Menu Jarin). Berikut ini akan dipaparkan hasil temuan kata makian pada film drama komedi Sasak OMJ (Ooo Menu Jarin).

a. Bentuk kata makian

Berdasarkan bentu bahasa, maka bentuk kata makian bahasa Sasak yang terdapat di film drama komedi Sasak OMJ (Ooo Menu Jarin) dapat diklarifikasikan menjadi dua, yaitu bentuk kata dasar dan makian bentuk frase. Kedua bentuk tersebut dapat dipaparkan secara rinci berikut ini.

1) Makian bentuk kata dasar

Kata dasar adalah kata yang belum diberi imbuhan dengan kata lain, kata dasar adalah kata yang menjadi dasar awal pembentukan kata yang lebih besar. Seperti bentuk dibawaah ini.

Table 2. Film Drama Komedi Sasak OMJ (Ooo Menu Jarin).

\begin{tabular}{|c|c|c|c|c|}
\hline No & Glos & Arti & Kutipan & Episode \\
\hline 1 & Jadiq & Haram & $\begin{array}{l}\text { Jadiq. Menghalangi } \\
\text { doang ini sudah } \\
\text { meong-meong yang } \\
\text { kuraang ajaritu } \\
\text { Haram menghalangi } \\
\text { saja ini sudah kucing- } \\
\text { kucing yang kurang } \\
\text { ajar itu }\end{array}$ & $\begin{array}{l}\text { Episode } \\
1\end{array}$ \\
\hline 2 & Sundes & Pezina & $\begin{array}{l}\text { Sundes ini kucing- } \\
\text { kucing yang kaeng- } \\
\text { kaeng tengah malem, } \\
\text { tidak tau orang } \\
\text { sedang istirahat tidur } \\
\text { nyenyak, } \\
\text { Pezina, ini kucing- } \\
\text { kucing tengah malam, } \\
\text { tidak tahu orang } \\
\text { sedang istirahat tidut } \\
\text { nyenyak }\end{array}$ & $\begin{array}{l}\text { Episode } \\
1\end{array}$ \\
\hline 3 & Berong & $\begin{array}{l}\text { Sejenis } \\
\text { penyakit } \\
\text { menular } \\
\text { (kusta) }\end{array}$ & $\begin{array}{l}\text { Mule menu berong } \\
\text { motor } n i \\
\text { Memang begini kusta } \\
\text { motor ini }\end{array}$ & $\begin{array}{l}\text { Episode } \\
2\end{array}$ \\
\hline 4 & Sampi & Sapi & $\begin{array}{lr}\text { Sampi } & \text { tidak } \text { ada } \\
\text { gunanya } & \text { dibiarkan }\end{array}$ & $\begin{array}{l}\text { Episode } \\
3\end{array}$ \\
\hline
\end{tabular}

\begin{tabular}{|l|l|l|l|l|}
\hline & & & $\begin{array}{l}\text { hidup, gosooookk } \\
\text { Sapi tidak ada } \\
\text { gunanya dibiarkan } \\
\text { hidup, gosooookkk }\end{array}$ & \\
\hline 5 & Bangke & Bangkai & $\begin{array}{l}\text { Bangke jamak terus } \\
\text { ape jari nek ko aku, } \\
\text { selapukn bekeluarge } \\
\text { nekm jak } \\
\text { Seperti bangkai terus } \\
\text { apa jadi punya saya } \\
\text { semuanya jadi } \\
\text { keluarga kamu }\end{array}$ & \\
& & \\
\hline
\end{tabular}

\section{KESIMPULAN DAN SARAN}

Dari hasil penelitian diatas, peneliti dapat menyimpulkan mengenai analisis kata makian pada sebuah film drama komedi Sasak OMJ (Ooo Menu Jarin) yang di tayangkan di stasiun Lombok Post TV adalah sebagai berikut.

1. Bentuk kata makian pada film drama komedi Sasak OMJ (Ooo Menu Jarin) menemukan dua bentuk kata makian yaitu bentuk kata dasar dan bentuk frase.

2. Fungsi kata makian pada film drama komedi Sasak OMJ (Ooo Menu Jarin), terdapat empat fungi kata makian menurut pandangan Andersson dan Trudfiil yaitu, a) fungsi "expletive" yang berarti penggunaan makian untuk menyatakan emosi dan tidak di tunjukkan langsung pada orang lain b) fungsi "abusive" yang berarti penggunaan makian yang langsung di tunjukkan pada orang lain c) fungsi "humorous" yang berarti penggunaan makian yang merujuk langsung pada orang lain, tetapi bukan dengan maksud menghina d) fungsi "auxiliary" yang berarti menggunakan makian yang tidak langsung merujuk pada orang lain, melainkan sekedar cara bicara (lezyspeaking), yang sering kali tidak sungguh-sungguh

3. Makna referensial kata makian pada film drama komedi Sasak OMJ (Ooo Menu Jarin) terdapat lima makna referensi yaitu, a) keadaan b) binatang c) benda-benda d) bagian tubuh dan e) profesi.

Berdasarkan hasil analisis dan data yang ditemukan melalui penelitian ini, penulis dapat menyampaikan saran kepada pembaca dan penelitian selanjutnya. 
1. Dari judul penelitian ini, kita bisa menambah wawasan mengenai kegunaan kata makian dalam berinteraksi dengan masyarakat yang seharusnya tidak lazim.

2. Lebih baik jangan dibudidayakan bahasa-bahasa kasar dalam berkomunikasi, karena dilihat dari perkembangan zaman banyak sekali bahasabahasa yang kurang dimengerti dan bahasa indonesia yang sesungguhnya dikatakan hampir punah.

\section{REFERENSI}

Arikunto, Suharsimi. 2012. Metode Penelitian Kauntitatif dan kualitatif Bandung:

Azizatul, fitri, 2014. Disfemisme Dalam Novel Nayla Karya Djenar Maesa Ayu. (Skripsi). Universitas Mataram.

Chaer, Abdul, dan Leony. 2004. Sosiolinguistik Perkenalan Awal. Jakarta: Rineka Cipta.

Junita, Ardi Susanti, 2004. Analisis Penggunaan Disfemisme Dalam Masyarakat Sasak Dialek a-a Di Desa Aikmel Barat Dan Relevansinya Dengan Materi Pembelajaran Bahasa Indonesia Di SMP. (Skripsi). Universitas Mataram.

Lexy, J. M. 2002. Metodologi Penelitian Kualitatif, Cet. 13 Bandung: Remaja Rosdakarya.

Mahsun. 2007. Metode Penelitian Bahasa: Tahapan Strategi.Metode dan Tekniknya. Edisi Revisi. Jakarta: PT Raja Grafindo Persada.

Sugiyono. 2009. Metode Penelitian Kuantitatif, kualitatif dan R \& D. Bandung: Alfabeta.

Wijana dan R 2013. Sosiolinguistik, Kajian Teori dan Analisis. Yogyakarta. Pustaka Pelajar.

2006. Sosiolinguistik, Kajian Teori dan Analisis. Edisi 1 Yogyakarta: Pustaka Pelajar.

http://Indonesiaindonesia.com/f/79679-definisipengertian-bahasa/ Diambil pada tanggal 10 Desember 2015. 